Bangladesh J. Sci. Ind. Res. 42(4), 465-474., 2007

\title{
Propagation of Heavy Metals in Poultry Feed Production in Bangladesh.
}

\author{
M. Shahidul Islam, ${ }^{a *}$ M. Azizul Islam Kazi, ${ }^{a}$ M. Moazzem Hossain, ${ }^{a}$ \\ M. Aminul Ahsan, ${ }^{a}$ and A. M. M. Maruf Hossain ${ }^{b}$ \\ ${ }^{a}$ BCSIR Laboratories, Dhaka and ${ }^{b}$ Department of Soil, Water and Environment, \\ University of Dhaka, Dhaka-1000, Bangladesh
}

\begin{abstract}
Poultry is one of the major protein sources for people in Bangladesh. It is a promising sector. It requires large scale feed production activities. There are various sources of raw materials for poultry feed production. In many ways these sources can be associated with anthropogenic heavy metal pollution. It is better to monitor any probable propagation of heavy metals into the food chain through the final feeds rather than the various raw materials for feeds. Three widely used feeds Usha, Fresh, and Saudi-Bangla feeds were selected for the study. Cadmium, lead, arsenic, mercury, selenium, chromium, manganese, nickel, copper, and zinc contents of all samples were measured. The detected maximum and minimum concentrations of these elements were found to be: $0.1852 \mathrm{ppm}$ and $0.0232 \mathrm{ppm}$ for cadmium, $20.6498 \mathrm{ppm}$ and $0.6019 \mathrm{ppm}$ for lead, $0.7640 \mathrm{ppm}$ and $0.0069 \mathrm{ppm}$ for arsenic, $0.0579 \mathrm{ppm}$ and $0.0116 \mathrm{ppm}$ for mercury, $0.0347 \mathrm{ppm}$ and $0.0069 \mathrm{ppm}$ for selenium, $5.7875 \mathrm{ppm}$ and $0.0926 \mathrm{ppm}$ for chromium, $302.2001 \mathrm{ppm}$ and 0.0695 ppm for manganese, $5.1625 \mathrm{ppm}$ and $0.0125 \mathrm{ppm}$ for nickel, $37.5725 \mathrm{ppm}$ and $0.0463 \mathrm{ppm}$ for copper, and $422.3023 \mathrm{ppm}$ and $0.0232 \mathrm{ppm}$ for zinc. The "Poultry Feed Reference Standards, February 2002", prepared by Ministry of Fisheries and Livestock, Govt. of the People's Republic of Bangladesh contains no standards for the heavy metals as contaminants into poultry feeds which demands immediate attention.
\end{abstract}

Key words: Heavy metal, Poultry feed, Environmental health.

\section{Introduction}

Over the last several years poultry has become a very popular and promising sector in Bangladesh. A large section of Bangladesh people consume poultry meat and egg to fulfill their protein demand. There are many commercial producers of poultry feed in Bangladesh. Three widely used feeds - Usha, Fresh, and Saudi-Bangla feeds were selected for the study.

*Corresponding author 
The raw materials for the production of poultry feed are of various origin. The exposure of these sources onto various anthropogenic pollutants, especially the heavy metals may affect our food chain through the feeds. Some of the heavy metals are ubiquitous in nature also. Heavy metals are specially regarded with the toxicological as well as the carcinogenic effects. Day by day the sources and extents of anthropogenic pollution are increasing in Bangladesh.

In Bangladesh, the tannery, ceramic, textile dying and sulfuric acid producing industrial sites are especially associated with heavy metal pollution. The disposal points of these sorts of industrial sites are reported to discharge $\mathrm{Cd}, \mathrm{Pb}, \mathrm{Mn}, \mathrm{Ni}, \mathrm{Cu}$, and $\mathrm{Zn}$ in excessive concentrations which are further concerned with the contamination of soils, vegetation, and water bodies (Kashem and Singh, 1999). Almost all of the tanning industries in Bangladesh tan hides using chrome tanning method which is associated with vigorous chromium contamination both in liquid and solid waste form disposal. Moreover arsenic contamination through groundwater is taking severe in many parts of the country.

There has been a noticeable control on the use of persistent organic pollutants (POP's) over the last several years. Heavy metal contamination demands similar attention. Heavy metals entering into food chain through different sources must be properly monitored for planning and implementation of mitigation strategies. This study is aimed at exploring heavy metal status of poultry feeds commercially produced in Bangladesh.

The heavy metals are described as those metals which have atomic number greater than iron (atomic number 26) or having density greater than $5 \mathrm{gcm}^{-3}$. The heavy metals of greater concern include cadmium, lead, arsenic, mercury, selenium, and chromium. Though chromium (III) is required as micronutrient for humans and some other animals (NRC, 1980), other mineral elements of nutritional significance which also fit in this category include vanadium, manganese, iron, cobalt, copper, zinc, and molybdenum (Henry \& Miles, 2001). Cadmium, lead, arsenic, mercury, selenium, chromium, manganese, nickel, copper, and zinc contents of three mostly used commercial poultry feeds were determined to study the risk of heavy metal contamination of food chain through this sector.

\section{Materials and Methods}

\section{Sampling:}

Sampling was done at the Nimtoli poultry market, Kotwali, Dhaka. Three most widely used feeds, namely Usha, Fresh, and SaudiBangla, were sampled. All kinds of broiler feeds (broiler-starter, broiler-grower, and broiler-finisher) were sampled from all, whereas the layer feed (layer-layer) was sampled from Usha and Fresh. 


\section{Sample groups with identification:}

The following three groups of samples were chosen for study.

- Usha poultry feeds (sample numbers 1-4)

- Sample 1: Starter feed for broiler

- Sample 2: Grower feed for broiler

- Sample 3: Finisher feed for broiler

- Sample 4: Layer feed for layer

- Fresh poultry feeds (sample numbers 5-8)

- Sample 5: Starter feed for broiler

- Sample 6: Grower feed for broiler

- Sample 7: Finisher feed for broiler

- Sample 8: Layer feed for layer

- Saudi-Bangla poultry feeds (sample numbers 9 - 11)

- Sample 9: Starter feed for broiler

- Sample 10: Grower feed for broiler

- Sample 11: Finisher feed for broiler

\section{Sample pretreatment:}

The samples were oven-dried at $105^{\circ} \mathrm{C}$ to remove all moisture and thereby the moisture contents of the samples were determined. The samples were oven-dried until the difference between two readings of weight was found negligible.

\section{Sample preparation method:}

The samples were prepared by using $\mathrm{HNO}_{3}$ $\mathrm{HClO}_{4}$ digestion (Kebbekus and Mitra, 1998). Since the samples were of organic origin with a very high organic content, $\mathrm{HNO}_{3}-\mathrm{HClO}_{4}$ digestion was preferred over the more common $\mathrm{HNO}_{3}$ extraction for the determination of heavy metals. This strongly oxidizing digestion decomposes organics quickly and efficiently.

\section{Sample analysis:}

Analyses of the prepared samples were performed through atomic absorption spectrophotometry. For arsenic determination of the prepared samples, hydrochloric acid (at least $11.6 \mathrm{ml}$ concentrated $\mathrm{HCl}$ for $100 \mathrm{ml}$ total sample) and KI (at least $1 \%$ ) were added.

\section{Results and Discussion}

Cadmium, Lead, Arsenic, Mercury, and Selenium:

Dry weight basis cadmium, lead, arsenic, mercury, and selenium levels of the analyzed samples are presented in Fig. 1.

The detected maximum and minimum concentrations were found to be: $0.1852 \mathrm{ppm}$ and $0.0232 \mathrm{ppm}$ for cadmium, $20.6498 \mathrm{ppm}$ and $0.6019 \mathrm{ppm}$ for lead, $0.7640 \mathrm{ppm}$ and $0.0069 \mathrm{ppm}$ for arsenic, $0.0579 \mathrm{ppm}$ and $0.0116 \mathrm{ppm}$ for mercury, and $0.0347 \mathrm{ppm}$ and $0.0069 \mathrm{ppm}$ for selenium.

In the commercial feed types, Fresh Poultry Feeds contained the minimum levels of these heavy metals. Lead, mercury and selenium were undetectable (lead at ppm level, while mercury and selenium at ppb). The starter and grower feeds for broiler also contained 


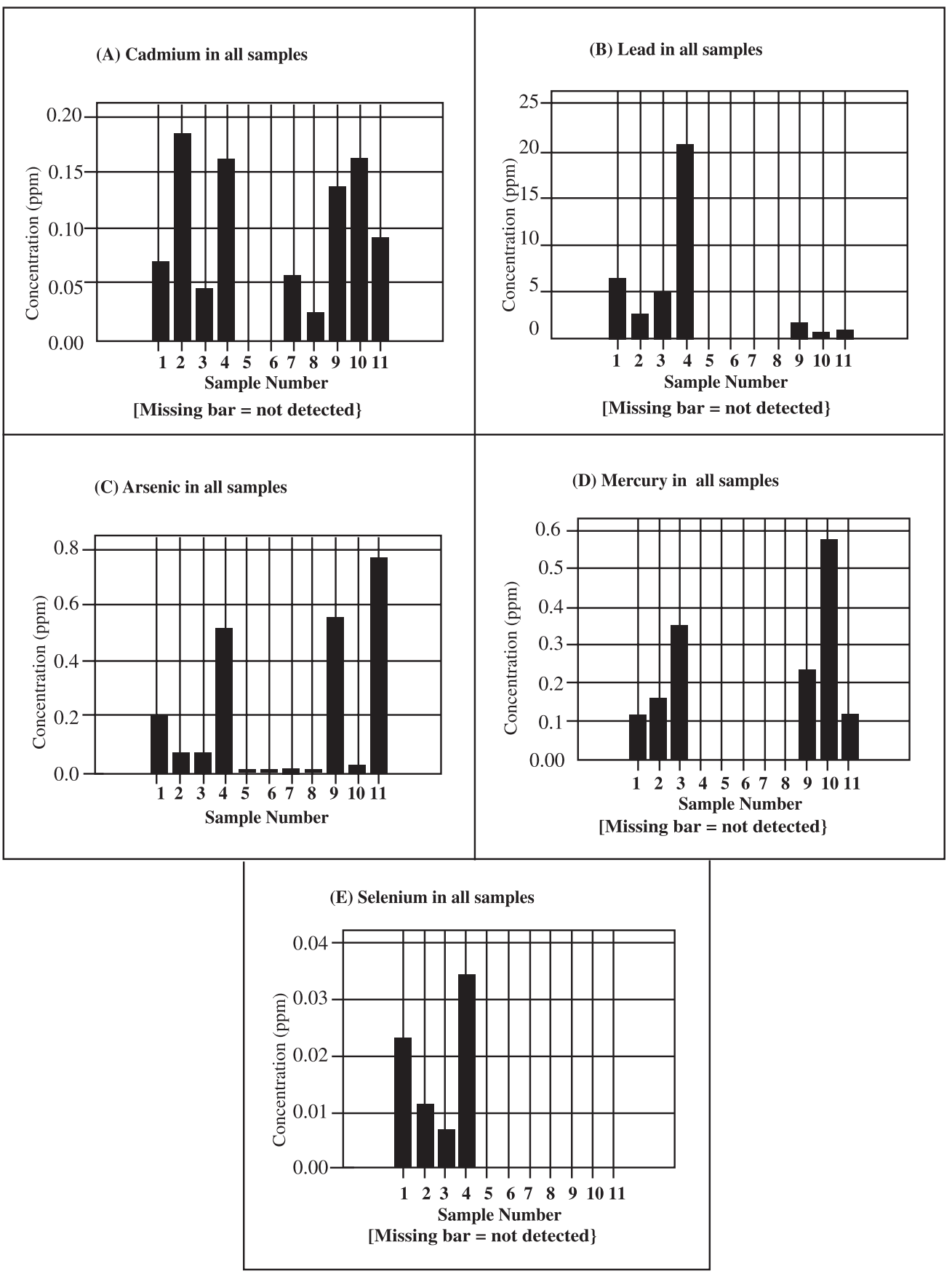

Fig. 1. (A) Cadmium in all samples; (B) Lead in all samples; (C) Arsenic in all samples; (D) Mercury in all samples; (E) Selenium in all samples 
undetectable cadmium, and the finisher and layer feeds contained very low cadmium (only $0.0579 \mathrm{ppm}$ and $0.0232 \mathrm{ppm}$ ) in comparison to the other sampled commercial feeds. The arsenic contents of the Fresh Poultry Feeds were also the least in the entire samples analyzed (maximum $0.0139 \mathrm{ppm}$ in broiler-finisher and minimum 0.0069 ppm in broiler-grower).

Cadmium and lead are nonessential nutrients that are of direct concern to human and livestock health and may accumulate in the body, particularly in the kidney, liver, and to a lesser extent in the muscle (Li et al., 2005). Most of us ingest heavy metals via food in our daily diets, although the quantity of heavy metals varies from place to place, depending on dietary habits (Louekari and Salminen, 1986) and levels of environmental pollution (Harrison and Laxen, 1984). Works suggested susceptibility of dairy cattle to the accumulation of cadmium and lead (Alonso et al., 2003).

Accumulation of cadmium has been observed in the ovaries and uteri of dairy cows (Smith, 1986) that may have an impact on reproduction. Despite the evidence of carcinogenic potency of cadmium in experimental animals, its carcinogenicity in humans is not well defined (Costa, 2000). However, 'International Agency for Research on Cancer' has classified cadmium and its compounds as a Group I human carcinogen (IARC, 1993). The effects of acute cadmium poisoning in humans are very serious. Among them are high blood pressure, kidney damage, destruction of testicular tissue, and destruction of red blood cells (Manahan, 1997).

Earlier this century, the majority of poisoning cases in animals resulted from lead consumption (NRC, 1980). Consumption of lead-containing paint chips also resulted in numerous cases of toxicosis in humans and animals (Henry \& Miles, 2001). Lead accumulates in bones and appears to be relatively immobile. Birds absorb approximately $10 \%$ of dietary lead (NRC, 1980). Lead compounds may have a variety of targets within the nervous system causing neurotoxicity (Bondy, 1988). Lead poisoning in humans causes severe dysfunction in the kidneys, reproductive system, liver, and the brain and central nervous system; causing sickness or death (Manahan, 1997).

As (III) is significantly more toxic than As (V) or the organic arsenicals, and the carcinogenicity and toxicity of the element mainly result from exposure to As (III) (Costa, 2000). Symptoms of exposure include severe inflammation of the gastrointestinal tract (Flower et al., 1979). Other evident features include facial edema, anorexia, anemia, upper respiratory distress, skin lesions, neurotic signs, and hepatomegaly.

Hassan et al. (1998) conducted experiments with multiple heavy metals including mercury added to water at high and low concentra- 
tions for 7 weeks and they found kidney as the main site of mercury accumulation. Mercury poisoning may cause gastrointestinal corrosion and irritation, such as vomiting, bloody diarrhea, and stomach pains. The symptoms with chronic intoxication may involve the oral cavity, the peripheral and central nervous system, and the kidneys (Nielsen and Grandjean, 2000).

Selenium is an essential micro-nutrient at low levels, but toxic at higher levels. The toxicity of selenium causes 'alkali disease' and 'blind staggers' in cattle and possibly carcinogenic (Manahan, 1997).

\section{Chromium, Manganese, Nickel, Copper, and Zinc:}

Dry weight basis chromium, manganese, nickel, copper, and zinc levels of the analyzed samples are presented in Fig. 2.

The detected maximum and minimum concentrations were found to be: $5.7875 \mathrm{ppm}$ and $0.0926 \mathrm{ppm}$ for chromium, 302.2001 ppm and 0.0695 ppm for manganese, 5.1625 ppm and 0.0125 ppm for nickel, 37.5725 ppm and $0.0463 \mathrm{ppm}$ for copper, and $422.3023 \mathrm{ppm}$ and $0.0232 \mathrm{ppm}$ for zinc.

In the commercial feed types, Fresh Poultry Feeds contained the minimum levels of these heavy metals. The chromium contents were below $1.5 \mathrm{ppm}$ while in the other two commercial feeds sampled, the average value was several ppm. In case of nickel the high- est value was $0.0287 \mathrm{ppm}$ in the Fresh Poultry Feeds while the other feeds contained several ppm of nickel in average. The most drastic differences were observed in cases of manganese, copper, and zinc. These three heavy metals were present at below 0.6 ppm level in the Fresh Poultry Feeds where many values were much less. But in case of the other two commercial feeds these contents are large approaching hundred to several hundreds of ppm in average.

Chromium as heavy metal has no adverse effect. The trivalent form of chromium is considered as essential for normal carbohydrate and lipid metabolism (NRC, 1980). Little toxic effect is attributed to trivalent chromium when present in large concentrations. However, $\mathrm{Cr}$ (III) is ubiquitous in nature, occurring in air, water, soil, and biological materials. The major concern about chromium is the $\mathrm{Cr}$ (VI) form which has carcinogenic behavior in humans. The most important toxic effects after contact, inhalation, or ingestion of hexavalent chromium compounds include dermatitis, allergic and eczematous skin reactions, skin and mucous ulcerations, perforation of the nasal septum, allergic asthmatic reactions, bronchial carcinomas, gastro-enteritis, hepatocellular deficiency, and renal oligo-anuric deficiency (Baruthio, 1992).

Manganese is required for humans as being a component of pyruvate carboxylase and probably other metallo-enzymes (Chaney, 1992). It is relatively non-toxic to animals, 


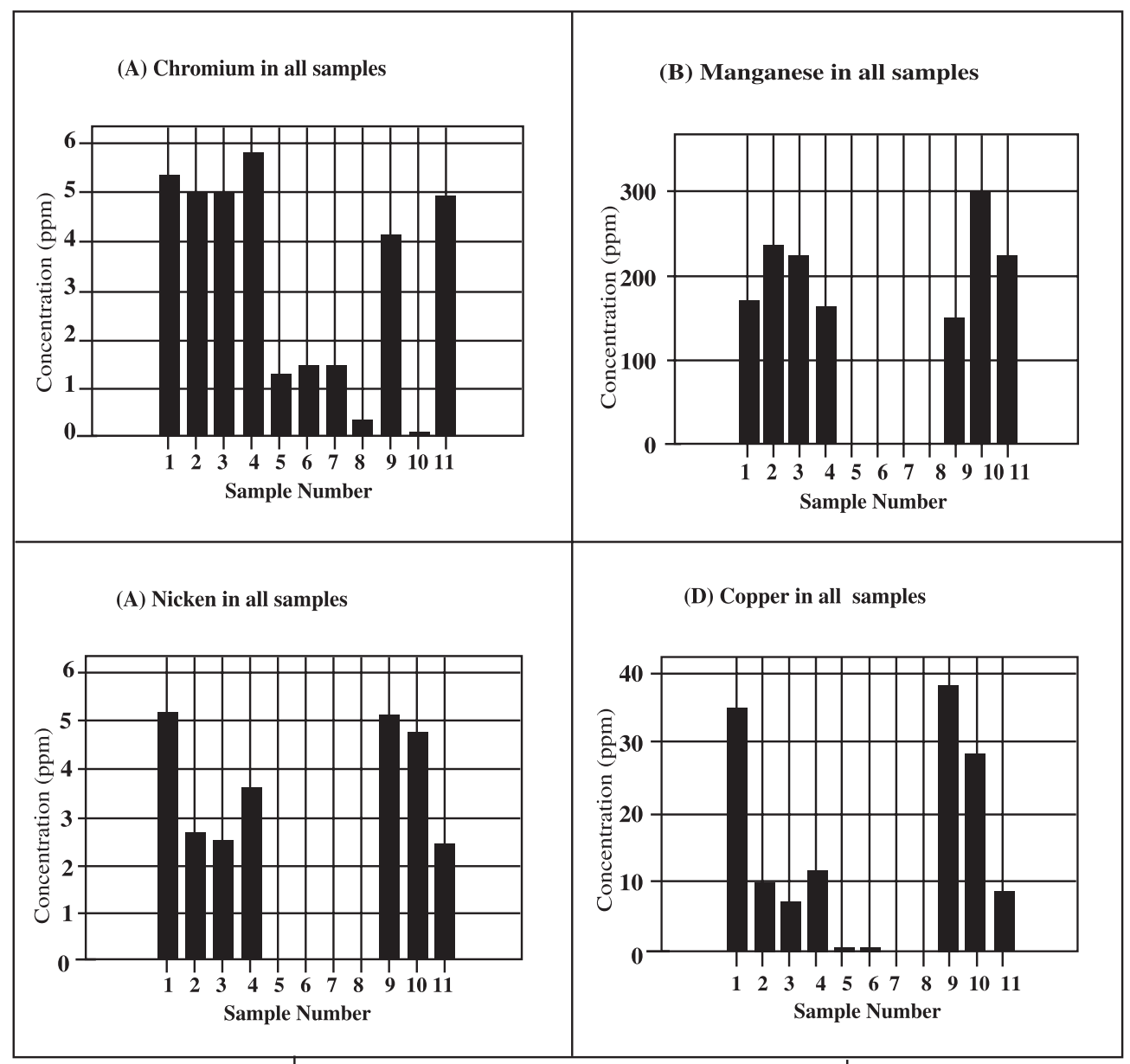

(E) Zinc in all samples

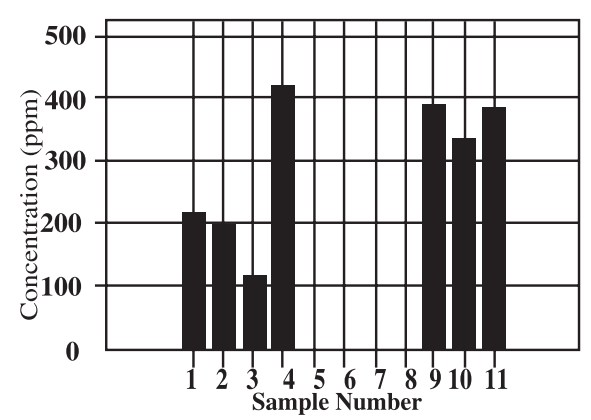

[Missing bar $=$ not detected]

Fig. 2. (A) Chromium in all samples; (B) Manganese in all samples; (C) Nickel in all samples; (D) Copper in all samples; (E) Zinc in all samples. 
and toxic to plants at higher levels (Manahan, 1997).

Nickel has been implicated as an essential trace metal in experimental animals (Costa, 2000). In human, nickel is important only as its distribution have been associated with several pathological states (Mertz, 1970). Though nickel has many occupational and inhalation toxicological effects, nickel compounds are also potent carcinogens in experimental animal models (Costa, 2000).

Copper is an essential micro-nutrient in humans as it functions as a co-factor for many enzymes (Chaney, 1992). It is not very toxic to animals, and toxic to plants and algae at moderate levels (Manahan, 1997).

Zinc is also an essential micro-nutrient in humans. It is essential element in many metallo-enzymes. It is present in gustin, a salivary polypeptide, that appears to be necessary for normal development of test buds. In both children and adults zinc deficiencies result in poor wound healing (Chaney, 1992). At higher levels it is toxic to plants (Manahan, 1997).

\section{Comparison of data with the standards:}

In the "Poultry Feed Reference Standards, February 2002", prepared by Ministry of Fisheries and Livestock, Govt. of the People's Republic of Bangladesh, there are the requirements of some heavy metals mentioned as nutrients. But as contaminant no standards in terms of maximum acceptable limit for the heavy metals was mentioned.
The requirements included four heavy metals (selenium, manganese, copper, and zinc) as micro-nutrient. All these four elements are essential micro-nutrients in humans at various levels. But heavy metals are more likely as contaminant than as nutrient and the most hazardous cadmium, lead, arsenic, mercury, and chromium should be the major concern in discussing heavy metals in poultry.

At the document, selenium was referred to as nutrient at (0.3-0.4) ppm level in starter, grower, and finisher feeds for broiler, and 0.3 ppm in layer feed of layer. In the samples selenium was present only in Usha Poultry Feeds but the values are much lower than the requirement as nutrient. The layer-layer feed contained the highest value of $0.0347 \mathrm{ppm}$.

Manganese was mentioned as nutrient at (60-120) ppm in starter and grower feeds for broiler, (100-120) ppm in finisher feed for broiler, and (60-66) ppm in layer feed of layer. Except the Fresh Poultry Feed samples, all the other samples contained manganese very much exceeding the nutritional requirement. But as no standards were fixed for maximum permissible limit as contaminant, it can not be shown whether the contents in the samples were harmful. Again, Fresh Poultry Feed samples contained very much lower concentration of manganese (maximum $0.5788 \mathrm{ppm}$ ) which certainly will not suffice the nutritional requirement.

Copper was given to be required as nutrient at (5-8) ppm in starter and grower feeds for broiler and layer feed for layer, and (5-10) 
ppm in finisher feed for broiler. In Usha and Saudi-Bangla Feeds sampled, copper was found to be in the range for some but as high as 37.5725 ppm in others. But, Fresh Poultry Feeds contained much lower contents of copper (maximum 0.4399 ppm) which certainly will not suffice the nutritional requirements.

Zinc was mentioned as nutrient at (50-110) ppm in starter and grower feeds for broiler, (100-110) ppm in finisher feed for broiler, and (50-70) ppm in layer feed of layer. Except the Fresh Poultry Feed samples, almost all of the other samples contained zinc very much exceeding the nutritional requirement. But as no standards were fixed for maximum permissible limit as contaminant, it can not be calculated whether the contents in the samples were harmful. Again, Fresh Poultry Feeds contained very much lower contents of zinc (maximum 0.0579 ppm) which certainly will not suffice the nutritional requirements.

\section{Conclusion}

To maintain the food chain safe from the entering of heavy metals and the subsequent consequences, it is necessary to have definite standards for heavy metals for all possible pathways towards food chain. Then any phenomenon allowing heavy metals to enter into food chain beyond those limits can automatically be regarded as unsafe and will be directed for mitigation strategies.

So, in the national guideline, the chapter for all potentially harmful heavy metals should be included in a definite way as contaminant showing maximum permissible limits, rather than nutritional requirements for the micronutrients. And no one of the commercial poultry feeds selected and sampled fulfills the nutritional requirements as per selenium, manganese, copper, and zinc. But in terms of the most hazardous cadmium, lead, arsenic, mercury, and chromium; the Fresh Poultry Feeds contained appreciably less concentration and in many instances even not detectable, compared to the other two commercial poultry feeds (Usha and SaudiBangla) sampled.

\section{References}

Alonso, M.L., Montana, F.P. Miranda, M. Castillo, C. Hernandez, J. and Benedito. J.L. (2003) Cadmium and lead accumulation in cattle in NW Spain. Vet. Hum. Toxicol. 45: 128-130.

Baruthio, F. (1992) Toxic effects of chromium and its compounds; Biol Trace Elem Res. 32: 145-53.

Bondy, S.C. (1988) The neurotoxicity of organic and inorganic lead. In Metal Neurotoxicity, eds. S.C. Bondy and K.R. Prasad. CRC Press, Boca Raton, FL.

Chaney, S.G. (1992) Principles of nutrition II: micronutrients. In Thomas M. Devlin (ed.) Textbook of Biochemistry with Clinical Correlations, 3/e. John Wiley and Sons, Inc. pp. 1116-1147.

Costa, M. (2000) Trace elements: aluminum, arsenic, cadmium, and nickel. In Morton 
Lippmann (ed.) Environmental Toxicants: Human Exposures and Their Health Effects, 2/e. John Wiley and Sons, Inc. pp. 811-850.

Flower, B., Ishinishi, N. Tsuchiya, K. and Vahter M. (1979) Arsenic. In Handbook on the Toxicology of Metals, eds. L. Friberg, G. F. Nordberg, and V. B. Vouk, Elsevier NorthHolland Biomedical Press, New York. pp. 1721-1723.

Harrison, R.H., and Laxen D.P.H. (1984) Human Exposure to Lead and Its Effect in Lead Pollution, Causes and Control. Chapman and Hall, New York. pp 133-158.

Hassan, A., Saleh, R. Sobih, M. Wilson, S. and Reddy P. (1998). Effect of some heavy metal pollutants on the performance and immune system of chicks. Poult. Sci. 77 (Suppl. 1): 24.

Henry, P. R., and Miles. R.D. (2001) Heavy metals - vanadium in poultry. Cieência Animal Brasileira. 2(1): 11-26.

IARC. (1993) Cadmium and Cadmium Compounds, vol. 58, pp. 119-237. IARC Monographs on the Evaluation of Carcinogenic Risks to Humans. Lyon: International Agency for Research on Cancer.

Kashem, M.A., and Singh. B.R. (1999) Heavy Metal Contamination of Soil and Vegetation in the Vicinity of Industries in Bangladesh. Water, Air, \& Soil Poll. 155: 347-361.

Kebbekus, B.B., Mitra. S. (1998) Environmental Chemical Analysis. Pub. Blackie Academic \& Professional. London.
Li, Y., McCory, D.F. Powell, J.M. Saam, H. and Jackson-Smith D.2005. J. Dairy Sci. 88: 2911-2922.

Louekari, K., and Salminen. S. (1986) Intake of heavy metals from food in Finland, West Germany, and Japan. Food. Addit. Contam. 3: 355-362.

Manahan, S.E. (1997) Environmental Science and Technology. CRC Press/Lewis Publishers, Boca Raton, FL.

Mertz, M. (1970) Some aspects of nutritional trace element research. Fed. Proc. 29:14821488.

Ministry of Fisheries and Livestock, the Govt. of People's Republic of Bangladesh. (2002) Poultry Feed Reference Standards, Bangladesh.

Nielsen, J.B., and P. Grandjean. (2000). Mercury. In Morton Lippmann (ed.) Environmental Toxicants: Human Exposures and Their Health Effects, 2/e. John Wiley and Sons, Inc. pp. 563-575.

NRC. (1980) Mineral Tolerance of Domestic Animals. National Academy Press, Washington, DC.

Smith, R.M. (1986) Effects of Long-term, Lowlevel Oral Cadmium on Performance, Blood Parameters, and Tissue and Milk Mineral Concentrations of Dairy Cattle through First Gestation and Subsequent Lactation. Ph.D. Diss., Pennsylvania State University, University Park.

Received : August 09, 2007;

Accepted : October 29, 2007 